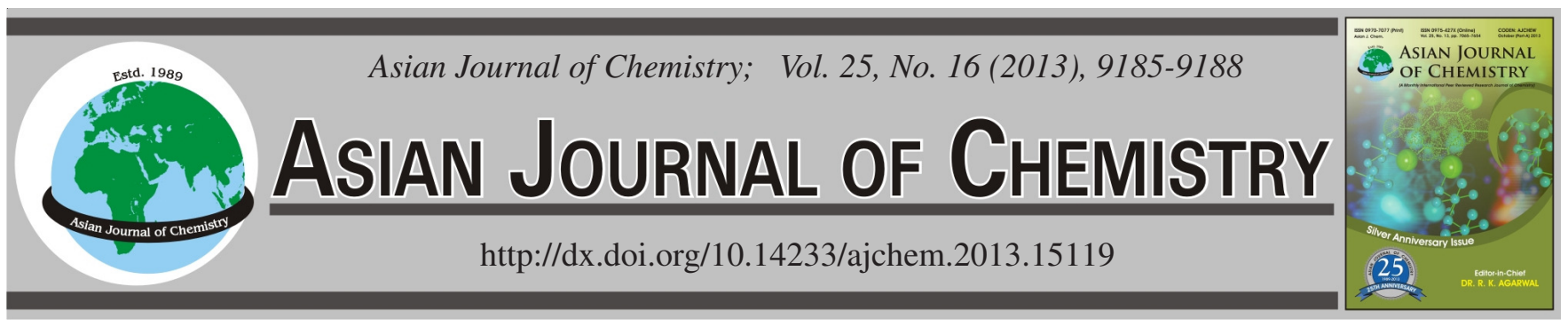

\title{
Vibrational Spectroscopic Investigation of Tetracyanopalladate Bridged Two Dimensional Coordination Polymer Compounds of Pyrimidine
}

\author{
Y. AKKAYA ${ }^{1}$, S. AKYUZ ${ }^{2, *}$ and T. AKYUZ ${ }^{2}$
}

${ }^{1}$ Department of Physics, Istanbul University, Vezneciler 34134, Istanbul, Turkey

${ }^{2}$ Department of Physics, Science and Letters Faculty, Istanbul Kultur University, Atakoy Campus, 34156 Istanbul, Turkey

*Corresponding author: Fax: +90 212 4658318; Tel: +90 212 4984401; E-mail: s.akyuz@iku.edu.tr

The two dimensional layered polymer compounds, $\mathrm{M}(\mathrm{PM})_{2} \mathrm{Pd}(\mathrm{CN})_{4}\{$ where $\mathrm{M}=\mathrm{Mn}, \mathrm{Zn}$ or Cd; PM = pyrimidine $\}$ have been prepared
for the first time and their FT-IR $\left(4000-400 \mathrm{~cm}^{-1}\right)$ and Raman $\left(4000-50 \mathrm{~cm}^{-1}\right)$ spectra are reported. The compounds built up of $\left[\mathrm{M}(\mathrm{PM})_{2}\right]^{2+}$
cations and square-planar $\left[\mathrm{Pd}(\mathrm{CN})_{4}\right]^{2-}$ anions, which are linked by the bridging $\mu_{2}-\mathrm{CN}^{-}$groups. Pyrimidine was coordinated to $\mathrm{M}(\mathrm{II})$
through one of the nitrogen atom of its heterocyclic ring, as monodentate ligand. Vibrational assignments are given for the bands arising
from the tetracyanopalladate layers and coordinated pyrimidine. The main bands of the vibrational spectra in the low frequency region
were assigned to the stretching and deformational vibrations $\{v(\mathrm{Pd}-\mathrm{C}), \delta(\mathrm{PdCN}), \pi(\mathrm{PdCN}), \delta(\mathrm{CPdC})\}$ originating from the host lattices.

Key Words: Coordination compounds, IR and Raman spectra, Pyrimidine complexes, Tetracyanopalladate.

ᄂ - - - - - - - - - - - - - - - - - - - - - - - - - - - -

\section{INTRODUCTION}

Pyrimidine is the parent heterocycle of important group of compounds that have been extensively studied due to their occurrence in living systems ${ }^{1,2}$. It is the parent molecule of nucleosides and nucleotides. Many pyrimidine derivatives possess remarkable biological activity, including anticancer, antimalarial, antihistaminic and antimicrobial activities and used as medicine in the treatment of different diseases ${ }^{1-8}$. The pyrimidine ring system provides a potential binding site for metals and therefore any information on its coordinating properties is important for understanding the role of metal ions in biological systems.

It is well known that the $\mathrm{CN}^{-}$group builds up one (1D), two(2D) or three-dimensional (3D) frameworks ${ }^{9}$ by alternately binding one metal atom $(\mathrm{M})$ to another metal atom $\left(\mathrm{M}^{\prime}\right)$. Cyanometallate complexes often contain porous structures and can act as molecular sieves ${ }^{9,10}$. They also have been intensively investigated due to their potential application in sensing devices $^{11}$, in non-linear optic devices ${ }^{12}$ and the design of molecule-based magnets ${ }^{13,14}$

The well known Hofmann type two dimensional complexes, $\left\{\mathrm{M}(\mathrm{L})_{2} \mathrm{M}^{\prime}(\mathrm{CN})_{4}\right\}$, are build by stacking the two dimensional extended metal ( $\left.\mathbf{M}^{\prime}\right)$ cyanide layers ${ }^{9,15}$. The two dimensional layer is constructed by the alternate linkage between square-planar $\mathrm{M}^{\prime}(\mathrm{II})\left(\mathrm{M}^{\prime}=\mathrm{Ni}, \mathrm{Pd}\right.$ or $\left.\mathrm{Pt}\right)$ and octahedral M(II) $(\mathrm{M}=\mathrm{Mn}, \mathrm{Fe}, \mathrm{Co}, \mathrm{Ni}, \mathrm{Cu}, \mathrm{Zn}$ or $\mathrm{Cd})$ through the cyanide bridges. The octahedral coordination of M(II) is satisfied by four N-terminals of the cyano groups and two nitrogen atoms of the two N-donor ligands (L) in trans configuration, protruding above and below the network ${ }^{9}$. Bahat and Yurdakul ${ }^{16}$ reported the vibrational spectra of Hofmann type tetracyanonickelate and tetracyanocadmate complexes of pyrimidine $\left\{\mathrm{M}(\mathrm{PM})_{2} \mathrm{Ni}(\mathrm{CN})_{4}, \mathrm{PM}=\right.$ pyrimidine and $\mathrm{M}=\mathrm{Mn}, \mathrm{Fe}, \mathrm{Co}, \mathrm{Zn}$, $\mathrm{Ni}, \mathrm{Cu}$ or $\mathrm{Cd}$ and $\left.\mathrm{Cd}(\mathrm{PM})_{2} \mathrm{Cd}(\mathrm{CN})_{4}\right\}$. We have previously reported the IR spectra of $\mathrm{M}(4 \mathrm{APM})_{2} \mathrm{M}^{\prime}(\mathrm{CN})_{4}$ \{ where $\mathrm{M}=$ $\mathrm{Mn}, \mathrm{Zn}$ or $\mathrm{Cd} ; \mathrm{M}^{\prime}=\mathrm{Pd}$ or Pt; 4APM = 4-aminopyrimidine $\}$ complexes ${ }^{17}$. Continuing our work on the spectroscopic and structural aspects of the two-dimensional (2D) coordination polymers of the tetracyanometallate complexes, we now report the vibrational spectra of the $\mathrm{M}(\mathrm{PM})_{2} \mathrm{Pd}(\mathrm{CN})_{4}$. In this study the two dimensional layered polymer compounds, $\mathrm{M}(\mathrm{PM})_{2} \mathrm{Pd}(\mathrm{CN})_{4}$ \{where $\mathrm{M}=\mathrm{Mn}, \mathrm{Zn}$ or $\mathrm{Cd} ; \mathrm{PM}=$ pyrimidine have been prepared for the first time and their FT-IR (4000-400 $\mathrm{cm}^{-1}$ ) and Raman (4000-50 $\mathrm{cm}^{-1}$ ) spectra are reported. Vibrational assignments are given for the bands arising from the tetracyanopalladate layers and coordinated pyrimidine.

\section{EXPERIMENTAL}

All the chemicals used were reagent grade (Aldrich and Reidel) and used without further purification. The complexes were prepared by adding slightly more than two moles of 
pyrimidine and one mole of potassium tetracyanopalladate aqueous solution to one mole of $\mathrm{M}(\mathrm{II})$ chloride solution with constant stirring. The $\mathrm{C}, \mathrm{H}, \mathrm{N}$ analyses were carried out for all the samples and the results were found to fit well with the proposed formulae. The IR spectra of nujol mulls or $\mathrm{KBr}$ discs were recorded on a Bruker Tensor-27 FT-IR spectrometer (1 $\mathrm{cm}^{-1}$ resolution) with accumulation of 200 scans. Raman spectra were recorded using a Jasco NRS 3100 Raman micro-spectrometer (1800 lines/mm grating and high sensitivity cooled CCD). Either $532 \mathrm{~nm}$ or $748 \mathrm{~nm}$ diode laser was used as excitation source. The spectrometer was calibrated by using both the silicon phonon mode at $520 \mathrm{~cm}^{-1}$ and toluene vibrational wavenumbers. A $20 \times$ microscope objective (Olympus) was used to focus the laser and collect Raman scattering of the sample. The laser power during signal acquisition was 42.5 $\mathrm{mW}$ and 50 spectra were accumulated. Spectral resolution was $3.9 \mathrm{~cm}^{-1}$.

Spectral manipulations such as baseline adjustment, smoothing, obtaining the second derivative and band fitting procedures, were performed using GRAMS/AI 7.02 (Thermo Electron Corporation) software package. Band fitting was done using Gaussian function and fitting was undertaken until reproducible and converged results were obtained with squared correlations better than $r^{2} \sim 0.99999$. The second derivative profile gives valuable information about the position of the bands and band widths. Thus for the band fitting procedure (to locate the position of the peaks), the second derivative of the absorption spectrum was used as a guide.

\section{RESULTS AND DISCUSSION}

FTIR (4000-400 $\left.\mathrm{cm}^{-1}\right)$ and Raman spectra $\left(2400-20 \mathrm{~cm}^{-1}\right)$ of the $\mathrm{M}(\mathrm{PM})_{2} \mathrm{Pd}(\mathrm{CN})_{4}$ \{where $\mathrm{M}=\mathrm{Mn}, \mathrm{Zn}$ or $\mathrm{Cd}$; $\mathrm{PM}=$ pyrimidine complexes are given in Figs. 1 and 2, respectively. The vibrational spectra of the complexes are very similar to each other, indicating that they have analogous structures.

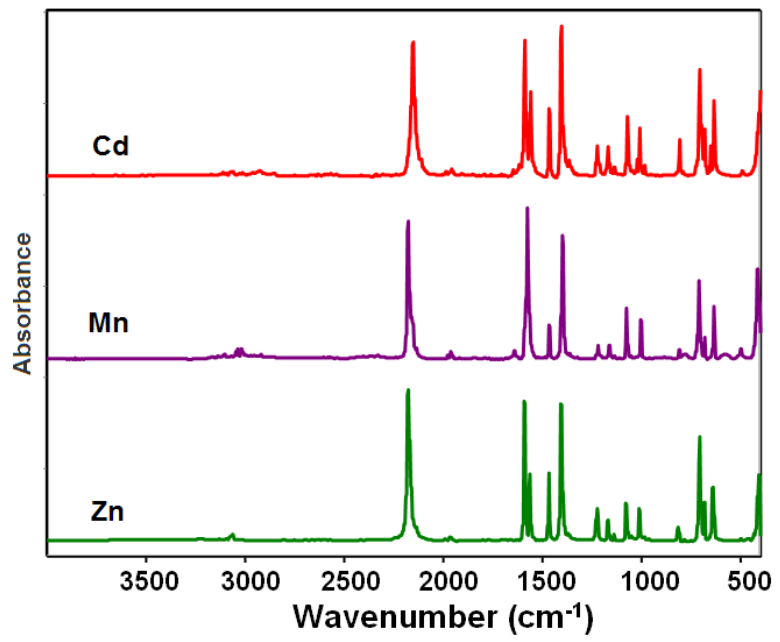

Fig. 1. FT-IR spectra of $\mathrm{M}(\mathrm{PM})_{2} \mathrm{Pd}(\mathrm{CN})_{4}$ complexes $\{$ where $\mathrm{PM}=$ pyrimidine, $\mathrm{M}=\mathrm{Cd}, \mathrm{Mn}$ or $\mathrm{Zn}$ \}

Vibrations of pyrimidine: The vibrational wavenumbers of pyrimidine are tabulated in Table- 1 in comparison with those

TABLE-1

WAVENUMBERS $\left(\mathrm{cm}^{-1}\right)$ OF PYRIMIDINE IN M(PM $)_{2} \mathrm{Pd}(\mathrm{CN})_{4}$ COMPLEXES

\begin{tabular}{|c|c|c|c|c|c|c|c|c|c|}
\hline \multirow{3}{*}{ Tentative assignment $t^{20}$} & \multicolumn{3}{|c|}{ Pyrimidine IR } & \multicolumn{6}{|c|}{$\mathrm{M}(\mathrm{PM})_{2} \mathrm{Pd}(\mathrm{CN})_{4}$ complexes $(\mathrm{M}=\mathrm{Cd}, \mathrm{Mn}$ or $\mathrm{Zn})$} \\
\hline & \multirow{2}{*}{$\frac{-}{\text { Liquid }^{18}}$} & \multirow{2}{*}{$\begin{array}{c}\text { This } \\
\text { Study } \\
\end{array}$} & \multirow{2}{*}{$\frac{\mathrm{Ar}}{\text { Matrix }^{20}}$} & \multicolumn{2}{|c|}{$\mathrm{Cd}$} & \multicolumn{2}{|c|}{$\mathrm{Mn}$} & \multicolumn{2}{|c|}{$\mathrm{Zn}$} \\
\hline & & & & IR & $\mathrm{Ra}$ & IR & $\mathrm{Ra}$ & IR & $\mathrm{Ra}$ \\
\hline $2 \mathrm{xv}_{4}$ & 3138 & 3132 & 3138 & 3128 & 3135 & - & - & - & - \\
\hline $\mathrm{v}_{1} ; \mathrm{v}(\mathrm{CH}) ; \mathrm{A}_{1}$ & 3084 & 3085 & 3091 & 3093 & 3100 & 3067 & - & 3070 & - \\
\hline$v_{2} ; v(\mathrm{CH}) ; \mathrm{A}_{1}$ & 3050 & 3049 & 3057 & 3065 & 3064 & - & - & 3061 & - \\
\hline$v_{12} ; v(\mathrm{CH}) ; \mathrm{B}_{2}$ & 3038 & 3039 & 3052 & 3059 & 3054 & - & - & - & - \\
\hline$v_{3} ; v(C H) ; A_{1}$ & 3038 & 3022 & 3041 & 3029 & 3037 & 3047 & - & - & - \\
\hline$v_{13} ; v_{\text {ring }} ; B_{2}$ & 1571 & 1568 & 1571 & 1589 & 1582 & 1577 & 1579 & 1591 & 1589 \\
\hline$v_{4} ; v_{\text {ring }} ; A_{1}$ & 1564 & 1549 & 1567 & 1562 & 1558 & 1563 & 1560 & 1564 & 1560 \\
\hline$v_{14} ; \delta(\mathrm{CH}) ; \mathrm{B}_{2}$ & $1466^{*}$ & 1467 & 1465 & 1466 & 1462 & 1465 & 1463 & 1470 & 1465 \\
\hline$v_{5} ; \delta(\mathrm{CH}) ; \mathrm{A}_{1}$ & $1398 *$ & 1397 & 1401 & 1406 & 1399 & 1399 & 1398 & 1406 & 1403 \\
\hline$v_{15} ; \delta(\mathrm{CH}) ; \mathrm{B}_{2}$ & $1375^{*}$ & 1378 & 1374 & 1367 & 1367 & 1372 & 1366 & 1370 & 1366 \\
\hline$v_{16} ; \delta(\mathrm{CH})+v_{\text {ring }} ; B_{2}$ & 1228 & 1225 & 1223 & 1227 & 1222 & 1228 & 1225 & 1231 & 1230 \\
\hline$v_{17} ; v_{\text {ring }} ; B_{2}$ & 1159 & 1157 & 1157 & 1169 & 1170 & 1163 & 1160 & 1170 & 1170 \\
\hline$v_{6} ; v_{\text {ring }} ; A_{1}$ & 1139 & 1139 & 1138 & 1143 & 1133 & 1138 & 1135 & 1140 & 1137 \\
\hline$v_{18} ; \delta(\mathrm{CH}) ; \mathrm{B}_{2}$ & $1070 *$ & 1072 & 1074 & 1073 & 1070 & 1075 & 1074 & 1080 & - \\
\hline$v_{7} ; v_{\text {ring }}+\delta_{\text {ring }} ; A_{1}$ & $1055^{*}$ & 1054 & 1071 & 1068 & 1066 & 1067 & - & 1070 & 1071 \\
\hline- & $1024 *$ & 1024 & - & 1026 & 1022 & 1027 & 1025 & - & - \\
\hline$v_{8} ;$ ring breath; $A_{1}$ & 990 & 991 & 990 & 1010 & 1007 & 1004 & 1004 & 1013 & 1008 \\
\hline$v_{10} ; \gamma_{C H} ; A_{2}$ & $987^{*}$ & - & - & 987 & 981 & - & - & 987 & 982 \\
\hline$v_{22} ; \tau_{\text {ring }}+\gamma_{\mathrm{CH}} ; \mathrm{B}_{1}$ & $812 *$ & 810 & 803 & 808 & - & 810 & - & 817 & - \\
\hline$v_{23} ; \tau_{\text {ring }}+\gamma_{\mathrm{CH}} ; \mathrm{B}_{1}$ & $719^{*}$ & 719 & 719 & 707 & - & 713 & - & 707 & - \\
\hline$v_{9} ; \delta_{\text {ring }} ; A_{1}$ & 681 & 679 & 678 & 684 & 682 & 681 & 681 & 685 & 683 \\
\hline$v_{19} ; \delta_{\text {ring }} ; \mathbf{B}_{2}$ & 626 & 624 & 621 & 637 & 635 & 638 & 636 & 643 & 638 \\
\hline$v_{11} ; \tau_{\text {ring }} ; A_{2}$ & 401 & - & - & 414 & 413 & 416 & - & 411 & 412 \\
\hline$v_{24} ; \tau_{\text {ring }} ; B_{1}$ & $344 * *$ & - & - & - & 345 & - & 346 & - & 351 \\
\hline
\end{tabular}




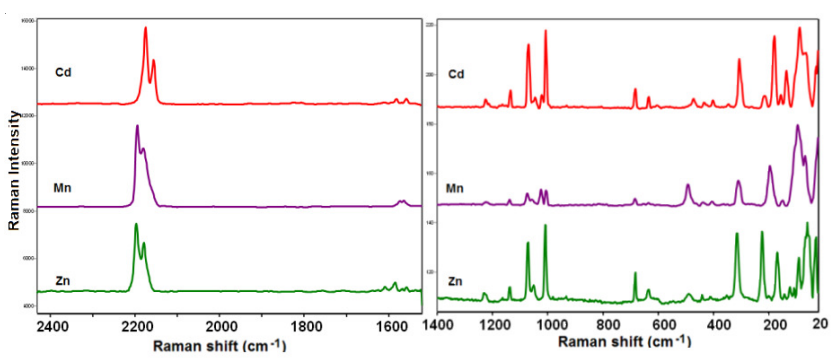

Fig. 2. Raman spectra of of $\mathrm{M}(\mathrm{PM})_{2} \mathrm{Pd}(\mathrm{CN})_{4}$ complexes $\{$ where $\mathrm{PM}=$ pyrimidine, $\mathrm{M}=\mathrm{Cd}, \mathrm{Mn}$ or $\mathrm{Zn}$ \}

of liquid ${ }^{16,18,19}$ pyrimidine and pyrimidine in an Ar matrix ${ }^{20}$. The previous studies showed that the ring breathing vibration of pyrimidine around $990 \mathrm{~cm}^{-1}$ is very sensitive to coordination state of the molecule. In the case of pyrimidine-metal complexes $^{20}$ or H-bonded-pyrimidine ${ }^{21}$, a shift to higher wavenumber in the ring breathing mode is used as a guide to the coordination state of the molecule ${ }^{21}$. In our previous study we have investigated monodentate and bidentate coordination effects on the vibrational wavenumbers of pyrimidine, by DFT calculations ${ }^{20}$. It was shown that in addition to the ring breathing mode, certain ring modes increase in value upon coordination of pyrimidine to a metal and it is possible to identify monodentate or bidentate coordination depending on the wavenumber shifts ${ }^{20}$. We clearly observed upward frequency shift on the ring breathing mode of pyrimidine and the other coordination sensitive modes, which were marked in bold in the Table-1. In Fig. 3, the 1620$900 \mathrm{~cm}^{-1}$ region of the IR spectra of liquid pyrimidine and $\mathrm{Cd}(\mathrm{PM})_{2} \mathrm{Pd}(\mathrm{CN})_{4}$ complex are shown. As seen in Fig. 3, $v_{8}$, $v_{13}, v_{15}, v_{17}$ modes of pyrimidine show upward shift upon coordination to $\mathrm{Cd}$. The comparison of the vibrational results of $\mathrm{M}(\mathrm{PM})_{2} \mathrm{Pd}(\mathrm{CN})_{4}$ complexes to those of monodentate and bidentate coordinated pyrimidine complexes ${ }^{21}$, allows us to conclude that pyrimidine molecule in the investigated complexes, is coordinated to metal through one of the pyrimidine ring nitrogen atoms as a monodentate ligand.

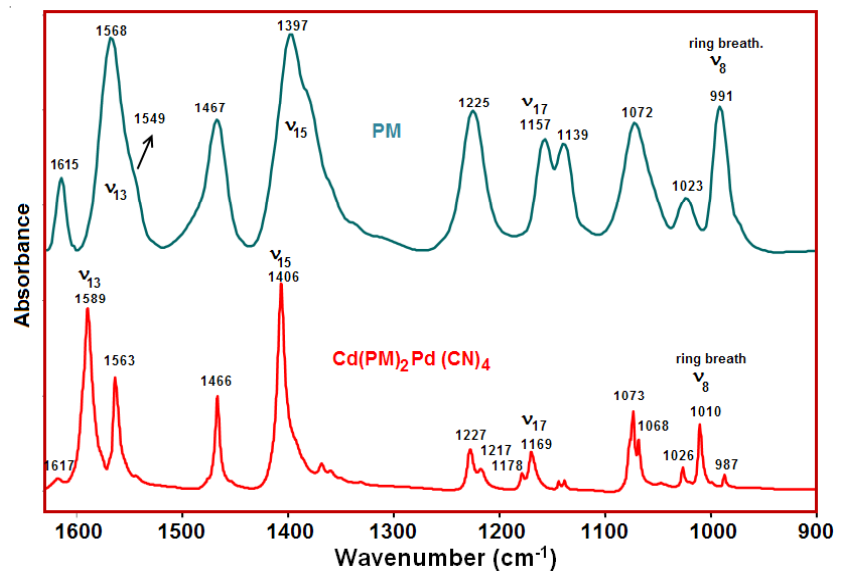

Fig. 3. $1620-900 \mathrm{~cm}^{-1}$ region of the IR spectra of liquid pyrimidine (above) and $\mathrm{Cd}(\mathrm{PM})_{2} \mathrm{Pd}(\mathrm{CN})_{4}$ complex (below)

In order to enhance resolution and identify the overlapping bands, we benefited from second derivative profiles and band component analysis. The band component analysis of the $1105-1040 \mathrm{~cm}^{-1}$ region of the IR spectrum of liquid pyrimidine is given in Fig. 4. As seen in Fig. 4, the $1054 \mathrm{~cm}^{-1}$

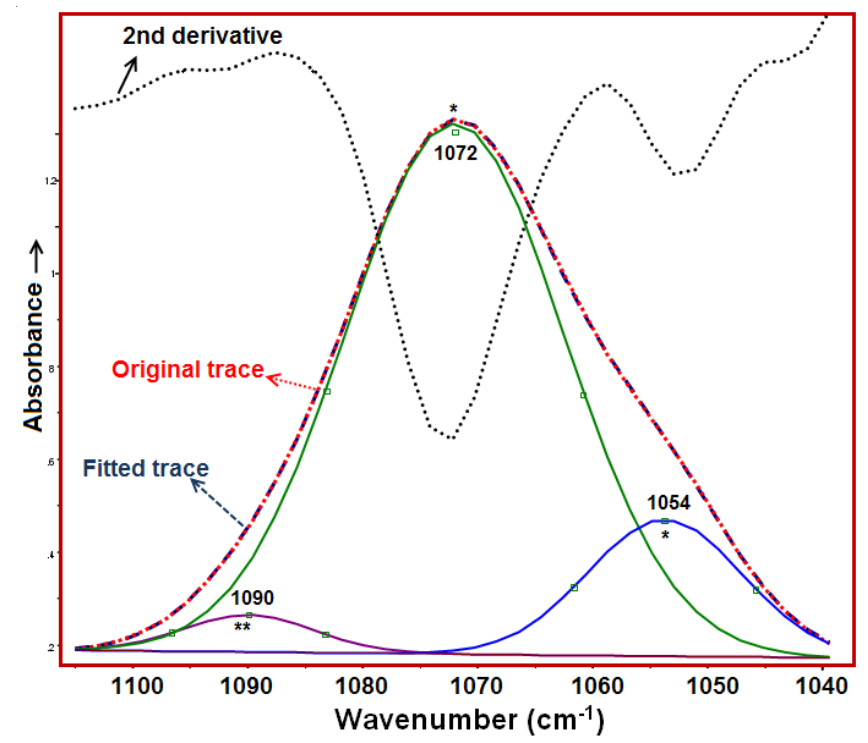

Fig. 4. Band component analysis of the $1105-1040 \mathrm{~cm}^{-1}$ region of the IR spectrum of liquid pyrimidine, in comparison with the second derivative profile of the absorption spectrum. 1072 and $1054 \mathrm{~cm}^{-1}$ bands are $v_{18}$ and $v_{7}$ modes, respectively and $1090 \mathrm{~cm}^{-1}$ band corresponds an overtone or combination vibrations

band of the liquid pyrimidine is identified both by band component analysis and by second derivative profile of the absorption spectrum. The other identified band at $1090 \mathrm{~cm}^{-1}$ is probably belongs to a combination or an overtone band.

Vibrations of $\mathrm{M}-\mathrm{Pd}(\mathrm{CN})_{4}$ polymeric sheets: The vibrational wavenumbers of the tetracyanopalladate polymeric sheets are tabulated in Table-2 together with the relevant data $^{17,22,23}$. Vibrational spectroscopy is an useful method for clarifying the coordination modes of cyano metal complexes, since cyano moieties give rise characteristic cyano stretching bands around $2200-2000 \mathrm{~cm}^{-1}$ from which their coordination modes; whether they act as terminal or bridging ligands, can be elucidated. Bands in the $2197-2144 \mathrm{~cm}^{-1}$ region are associated with bridging cyano moieties. That is observed in the IR and Raman spectra of the investigated complexes. The $\mathrm{CN}$ vibrational modes of the $\mathrm{M}(\mathrm{PM})_{2} \mathrm{Pd}(\mathrm{CN})_{4}$ complexes studied are found to be closer to those of Hofmann-type clathrates than that of the free $\mathrm{Pd}(\mathrm{CN})_{4}$ group $\left\{\right.$ e.g. $\left.\mathrm{K}_{2} \mathrm{Pd}(\mathrm{CN})_{4}\right\}$. Thus it is concluded that the polymeric sheet structure of the twodimensional network of M-NC-Pd units is preserved in the complexes $(\mathrm{M}=\mathrm{Mn}, \mathrm{Zn}$ or $\mathrm{Cd})$. The polymeric sheet structure of $\mathrm{M}(\mathrm{PM})_{2} \mathrm{Pd}(\mathrm{CN})_{4}$ compounds consists of a network of $\mathrm{Pd}(\mathrm{CN})_{4}$ groups. If a local $\mathrm{D}_{4 \mathrm{~h}}$ environment for $\mathrm{Pd}$ atom is assumed, one IR active $\left(\mathrm{E}_{\mathrm{u}}\right)$ and two Raman active $\left(\mathrm{A}_{1 \mathrm{~g}}\right.$ and $\left.\mathrm{B}_{\mathrm{gg}}\right) \mathrm{CN}$ stretching vibrations are expected. This is what we observed in the vibrational spectra of the $\mathrm{M}(\mathrm{PM})_{2} \mathrm{Pd}(\mathrm{CN})_{4}$ complexes. The assignment of the bands in the Raman spectra of the low wavenumber region was made by comparison of the corresponding spectra of $\mathrm{K}_{2} \mathrm{Pd}(\mathrm{CN})_{4} \cdot \mathrm{H}_{2} \mathrm{O}^{22}$, Hofmann-type clathrates $^{23}\left\{\mathrm{M}\left(\mathrm{NH}_{3}\right)_{2} \mathrm{Pd}(\mathrm{CN})_{4} .2 \mathrm{Bz}\right\}$ and $\mathrm{M}(4$-aminopyrimidine $)_{2} \mathrm{Pd}(\mathrm{CN})_{4}$ complexes $^{17}$. Comparison of the vibrational wavenumbers of the tetracyanopalladate sheets of the isostructural compounds provide a tentative assignment. In the case of Cd complex, the $\mathrm{CN}$ stretching wavenumbers are lower than those of the corresponding modes of the $\mathrm{Mn}$ or $\mathrm{Zn}$ complexes. A possible reason for the lower wavenumbers in the $\mathrm{Cd}$ 
TABLE-2

VIBRATIONAL WAVENUMBERS OF TETRACYANOPALLADATE GROUP VIBRATIONS ${ }^{\text {a }}$

\begin{tabular}{|c|c|c|c|c|c|c|c|c|}
\hline \multirow{2}{*}{ Assignment } & \multirow{2}{*}{$\mathrm{K}-\mathrm{Pd}-\mathrm{CN}^{\mathrm{b}}$} & \multicolumn{2}{|c|}{$\mathrm{M}-\mathrm{NH}_{3}-\mathrm{Pd}^{\mathrm{c}}$} & \multicolumn{2}{|c|}{ M-4APM-Pd ${ }^{d}$} & \multicolumn{3}{|c|}{ M-PM-Pd This study } \\
\hline & & $\mathrm{Cd}$ & $\mathrm{Mn}$ & $\mathrm{Cd}$ & $\mathrm{Mn}$ & $\mathrm{Cd}$ & $\mathrm{Mn}$ & $\mathrm{Zn}$ \\
\hline$v(\mathrm{CN}) \mathrm{E}_{\mathrm{u}}$ & 2138,2132 & - & - & 2165 & 2162,2149 & 2153 & 2177 & 2177 \\
\hline$v(\mathrm{Pd}-\mathrm{C}) \mathrm{E}_{\mathrm{u}}$ & 490 & 488 & 491 & 492 & 496 & 492 & 501 & 500 \\
\hline$\pi(\mathrm{PdCN}) \mathrm{A}_{2 \mathrm{u}}$ & $425^{*}$ & 428 & 428 & 434 & 436 & 427 & 433 & 436 \\
\hline$\delta(\mathrm{PdCN}) \mathrm{E}_{\mathrm{u}}$ & 377 & 401 & 408 & 419 & 415 & 406 & 416 & 412 \\
\hline$v(\mathrm{CN}) \mathrm{A}_{1 \mathrm{~g}}$ & $(2160)$ & - & - & (2189) & (2201) & (2176) & (2195) & (2197) \\
\hline$v(\mathrm{Pd}-\mathrm{C}) \mathrm{B}_{1 \mathrm{~g}}$ & $(443)^{*}$ & (484) & $(481)$ & $(471)$ & $(465)$ & $(470)$ & (489) & (488) \\
\hline$v(P d-C) A_{1 g}$ & $(425)$ & $(445)$ & $(441)$ & (427) & (431) & (430) & (431) & (438) \\
\hline$\pi(\mathrm{PdCN}) \mathrm{E}_{\mathrm{g}}$ & (299) & (296) & (304) & (305) & (301) & (305) & (310) & (310) \\
\hline$\delta(\mathrm{CPdC}) \mathrm{B}_{2 \mathrm{~g}}$ & $(163)^{*}$ & - & - & (169) & (186) & (178) & (193) & (196) \\
\hline$\delta(\mathrm{CPdC}) \mathrm{A}_{1 \mathrm{~g}}$ & $(101)^{*}$ & - & - & $(95)$ & (99) & (103) & (105) & (105) \\
\hline
\end{tabular}

${ }^{\mathrm{a}} \mathrm{IR}$ bands are given without parentheses; Raman bands are given in parentheses. ${ }^{b} \mathrm{~K}_{2} \mathrm{Pd}(\mathrm{CN})_{4} \cdot \mathrm{H}_{2} \mathrm{O}$, taken from ref. ${ }^{22}$. ${ }^{\mathrm{c}} \mathrm{Hofmann}$ type clathrates $\mathrm{M}(\mathrm{NH})_{3} \mathrm{Ni}(\mathrm{CN})_{4} \cdot 2 \mathrm{G}$ where $\mathrm{G}$ is the guest molecule (benzene, aniline or thiophene); taken from ref. ${ }^{23}$, except where indicated. ${ }^{\mathrm{d}} \mathrm{M}(4-$ Aminopyrimidine $)_{2} \mathrm{Pd}(\mathrm{CN})_{4}$ complexes, taken from ref. ${ }^{17}$. M-PM-Pd $=\mathrm{M}(\mathrm{PM})_{2} \mathrm{Pd}(\mathrm{CN})_{4}$. ${ }^{*}$ Our values.

complex is due to bigger Cd-NC bonds. According to the $\mathrm{X}$ ray crystallographic studies on Hofmann type compounds, the unit cell dimensions increase with the increasing ionic radius of the octahedral metal $(\mathrm{M})$, where square-planar metal $\left(\mathrm{M}^{\prime}\right)$ is the same ${ }^{24}$. Therefore probably unit cell dimensions of the Cd complex are bigger than the others.

\section{Conclusion}

IR and Raman spectroscopy provides a powerful means to assess the effects of coordination on PM and to determine its coordination mode. Based on the spectroscopic results it is concluded that PM acts as a monodentate ligand. The comparison of the vibrational wavenumbers of tetracyanopalladate sheet of the isostructural compounds lead us to express a tentative assignment for $\mathrm{Pd}-\mathrm{C}$ stretching, $\mathrm{PdCN}$ and $\mathrm{CPdC}$ bending vibrational modes.

\section{REFERENCES}

1. R.K. Murray, D.K. Granner, P.A. Mayes and V.W. Rodwell, Harper's Biochemistry, Prentice Hall International Inc., London, edn. 22, p. 333 (1990).

2. S.N. Pandeya, D. Sriram, G. Nath and E. De Clercq, IL Farmaco, 54, 624 (1999).

3. A.M. Rahatgaonkar and B.J. Ghiya, Asian J. Chem., 10, 958 (1998).

4. R.K. Kawadkar and B.J. Ghiya, Asian J. Chem., 10, 976 (1998).

5. P.B. Heda and B.J. Ghiya, Asian J. Chem., 11, 591 (1999).

6. R. Neekhara, B.J. Mishra and N.S.H.N. Moorthy, Asian J. Chem., 18, 1167 (2006).

7. N.L. Shirole, G.S. Talele, R.A. Fursule, S.J. Surana and K.S. Jain, Asian J. Chem., 18, 2673 (2006).
8. R.J.R. Rao, A.K.S.B. Rao, K. Swapna, B.B.Rani and Y.L.N. Murthy, Asian J. Chem., 24, 1837 (2012).

9. T. Iwamoto, In eds.: J.L. Atwood, J.E.D. Davies and D.D. MacNicol, Inclusion Compounds, Oxford University Press, Vol. 5, Ch. 6, p. 177 (1991).

10. A.J. Fletcher, E.J. Cussen, D. Bradshaw, M.J. Rosseinsky and K.M. Thomas, J. Am. Chem. Soc., 126, 9750 (2004).

11. N.A. Rakow and K.S. Suslick, Nature, 406, 710 (2000).

12. Q.-F. Xu, Q.-X. Zhou, J.-M. Lu, X.-W. Xia, L.-H. Wang and Y. Zhang, Polyhedron, 26, 4849 (2007).

13. J. Cernak, M. Orendac, I. Potocnak, J. Chomic, A. Orendacova, J. Skorsepa and A. Feher, Coord. Chem. Rev., 224, 51 (2002).

14. J. Cernak, J. Lipkowski, E. Cizmar, A. Orendacova, M. Orendac, A. Feher and M.W. Meisel, Solid State Sci., 5, 579 (2003).

15. Y. Tufan, C. Kilicer and F. Formali, Asian J. Chem., 22, 6791 (2010).

16. M. Bahat and S. Yurdakul, Spectrochim. Acta A, 58, 933 (2002).

17. S. Akyuz and T. Akyuz, J. Mol. Struct., 924-926, 37 (2009).

18. A.M. Wright, L.W. Joe, A.A. Howard, G.S. Tschumper and N.I. Hammer, Chem. Phys. Lett., 501, 319 (2011).

19. A. Destexhe, J. Smets, L. Adamowicz and G. Maes, J. Phys. Chem., 98, 1506 (1994).

20. S. Breda, I.D. Reva, L. Lapnski, M.J. Novak and R. Fausto, J. Mol. Struct., 786, 193 (2006).

21. E. Akalin and S. Akyuz, Vib. Spectr., 48, 233 (2008).

22. C. Mule, J. Nuss, R.E. Dinnebier and M. Jansen, Z. Anorg. Allg. Chem., 630, 1462 (2004).

23. B. Minceva-Sukarova, L. Andreeva and S. Akyuz, J. Mol. Struct., 834836, 48 (2007).

24. T. Iwamoto, In eds.: J.L. Atwood, J.E.D. Davies and D.D. MacNicol, Inclusion Compounds, Academic Press, London, Oxford University Press, Ch. 2, Vol. 5, p. 29 (1991); Ch. 6, Vol. 1, p. 177 (1984). 